\title{
Milestones in Molecular Mechanisms of Adipogenesis and Adipose Tissue Plasticity
}

\author{
O.P. Shatova ${ }^{1}$; A.A. Zabolotneva ${ }^{1}$; M.B. Potievskiy²; A.V. Shestopalov ${ }^{3,4}$; \\ S.A. Roumiantsev ${ }^{1,4}$ \\ ${ }^{I}$ N. I. Pirogov Russian National Research Medical University \\ ${ }^{2}$ National Medical Research Radiological Centre \\ ${ }^{3}$ Dmitry Rogachev National Medical Research Center of \\ Pediatric Hematology, Oncology and Immunology \\ ${ }^{4}$ Center for Digital and Translational Biomedicine «Center for Molecular Health» \\ Moscow, the Russian Federation
}

\begin{abstract}
This review focuses on the problem of adipogenesis mechanisms and the biological role of adipose tissue (AT) in the human body. Over the past decades, various types of adipocytes have been identified and characterized-white, brown, beige, yellow, and pink. An important feature of AT is a high plasticity and the ability to transdifferentiate and de-differentiate into another cell type. In this case, the pathway of transformation mostly depends on adipocytes' cellular and metabolic microenvironment. The mechanisms of adipogenesis and the ways of its regulation remain not fully understood. The principal role in the terminal differentiation of preadipocytes is assigned to PPAR $\gamma$ and receptors activated by bone morphogenetic proteins, insulin, and cortisol. However, in chronic inflammation, adipogenesis is suppressed and old adipocytes increase the production of proinflammatory cytokines, which leads to the death of inflamed cells and hypertrophy of neighboring adipocytes. Thus, disruption of adipogenesis, premature aging of white adipocytes, perturbations in the metabolic and cellular microenvironment of preadipocytes, and early apoptosis of fat cells cause the development of insulin resistance and metabolically unhealthy obesity.(International Journal of Biomedicine. 2021;11(3):323-332.)
\end{abstract}

Key Words: adipose tissue $\bullet$ adipocytes $\bullet$ adipogenesis $\bullet$ transdifferentiation

For citation: Shatova OP, Zabolotneva AA, Potievskiy MB, Shestopalov AV, Roumiantsev SA. Milestones in Molecular Mechanisms of Adipogenesis and Adipose Tissue Plasticity. International Journal of Biomedicine.2021;11(3):323-332. doi:10.21103/Article11(3)_RA3

\section{Abbreviations}

AT, adipose tissue; BM, bone marrow; BMPs, bone morphogenetic proteins; BMAT, bone marrow adipose tissue; BMAC, bone marrow adipocytes; BAT, brown adipose tissue; BeAC, beige adipocytes; BrAC, brown adipocytes; BMI, body mass index; C/EBPs, CCAAT-enhancer binding proteins; FAs, fatty acids; FAHFAs, fatty acid esters of hydroxy FAs; HIF-1a, hypoxiainducible factor-1 $\alpha$; LDLR, low-density lipoprotein receptor; MCSs, mesenchymal stem cells; Myf5, myogenic factor 5; PDGFR $\alpha$, platelet-derived growth factor receptor $\alpha$; PPAR $\gamma$, peroxisome proliferator-activated receptor $\gamma$; ROS, reactive oxygen species; WAT, white adipose tissue; WAC, white adipocytes.

\section{Introduction}

Currently, we are facing a significant revision of understanding the biological role of adipose tissue (AT) in the human body. Over the past decades, various types of adipocytes have been identified and characterized - white, brown, beige, yellow, and pink. AT possesses a high degree of heterogeneity even within the same fat depot. An important feature of AT is a high plasticity and the ability to transdifferentiate and dedifferentiate into another cell type. In this case, the pathway 
of transformation mostly depends on adipocytes' cellular and metabolic microenvironment. Preadipocytes are formed from different progenitor cells: for instance, thermogenic adipocytes may have myogenic (like brown cell type) or adipogenic (like beige cell type) origin. The mechanisms of adipogenesis and the ways of its regulation remain not fully understood. The principal role in the terminal differentiation of preadipocytes is assigned to PPAR $\gamma$ and receptors activated by bone morphogenetic proteins, insulin, and cortisol. However, in chronic inflammation, adipogenesis is suppressed and old adipocytes increase the production of proinflammatory cytokines, which leads to the death of inflamed cells and hypertrophy of neighboring adipocytes. Thus, disruption of adipogenesis, premature aging of white adipocytes, perturbations in the metabolic and cellular microenvironment of preadipocytes, and early apoptosis of fat cells cause the development of insulin resistance and metabolically unhealthy obesity.

\section{Types of adipocytes}

AT is divided by localization and cell morphology into four main types: ${ }^{(1)}$ white, brown, beige, ${ }^{(2)}$ and yellow. The last type was identified in the bone marrow (BM) ${ }^{(3)}$ White adipose tissue (WAT) is characterized by heterogeneous localization and cellular composition. ${ }^{(2)}$ WAT is divided into visceral and non-visceral, which can be subdivided into subcutaneous and intradermal. ${ }^{(4)}$ Intradermal AT is involved in wound healing and hair development, ${ }^{(2)}$ whereas the main functions of subcutaneous AT are energy storing and hormone production. ${ }^{(4)}$ WAT consists of different cell types: white adipocytes (WAC), white preadipocytes, mesenchymal stem cells (MSCs), pericytes, monocytes, and macrophages. ${ }^{(2)}$ Visceral WAT differs from subcutaneous fat in cellular composition, increased resistin production, lower leptin secretion level ${ }^{(5)}$ and lower insulin sensitivity. ${ }^{\left({ }^{6}\right.}$ Therefore, the accumulation of visceral fat is associated with the development of metabolic syndrome, ${ }^{(2)}$ type 2 diabetes, cardiovascular failure, and fatty liver disease. ${ }^{(7)}$ Furthermore, visceral AT exhibits apparent metabolic differences: the rate of lipolysis and formation of free fatty acids (FAs) is significantly higher in visceral than in subcutaneous depot. ${ }^{(5)}$ It should be mentioned that storing fat on the thighs and trunk significantly reduces the risk of metabolic syndrome, ${ }^{(6)}$ and a high secretion of leptin prevents the development of neurodegenerative diseases. ${ }^{(5)}$ The loss of WAC in subcutaneous limb fat depots takes place in cases of lipodystrophic diseases, such as familial partial lipodystrophy and lipodystrophy caused by antiretroviral therapy in HIV-positive patients. This process is associated with simultaneous accumulation of visceral fat, including the areas of brown adipose tissue (BAT) localization. ${ }^{(8,9)}$ Hypertrophy of beige (induced brown) AT and its replacement with WAT in the dorso-cervical region is observed in HIV-positive patients. ${ }^{(10)}$ In these patients, lipodystrophy is paradoxically associated with metabolic signs of obesity - insulin resistance, hyperglycemia, hepatosteatosis, hypertension and dyslipidemia. ${ }^{(11,12)}$ Thus, deficiency of AT, as well as obesity, is associated with severe metabolic disorders.

BAT is localized in cervical, axillary, paravertebral and supraclavicular areas. The main functions of brown adipocytes
(BrAC) are adaptive thermogenesis ${ }^{(13)}$ and endocrine regulation of lipogenesis and adipogenesis. ${ }^{(14)}$ The number of BrAC decreases during aging. According to Rui et al., ${ }^{(13)}$ it may be evolutionary associated with human behavioral adaptation - clothes wearing.

According to the experimental data, a significant decrease in the number of $\mathrm{BrAC}$ in mice is associated with aging. ${ }^{(15)}$ Simultaneously, as the number of WAC increases, the transdifferentiation of BAT to WAT intensifies. The same results were presented in a study of biopsy samples of pericarotid cervical fat depots in humans. ${ }^{(16,17)}$ It should be mentioned that the complete absence of BAT in the body leads to fatal hypothermia and death in mice. ${ }^{(18)}$

Bone marrow adipose tissue (BMAT) is a separate depot of adipocytes in the human body ${ }^{(3)}$ It consists of constitutive fat tissue localized in the distal bones of the skeleton, as well as adjustable AT diffusely scattered in the spine and proximal limb bones and is responsible for interaction with environmental factors. ${ }^{(19)}$ BMAT plays an important role in bone metabolism and the regulation of osteoblast activity. ${ }^{(2)}$ Unlike BrAC and BeAC, BMAT does not express UCP-1. ${ }^{(19)}$ Reactions to adrenergic stimulation are expressed to a lesser extent in adipocytes of the BM than in white ones. ${ }^{(21)}$ Such resistance of yellow adipocytes manifests to a greater extent in the distal regions of the skeleton, where adipocytes have larger size and constitutive phenotypes. It is believed that adrenergic sensitivity of adipocytes is influenced by the cellular microenvironment. Importantly, women are more susceptible than men to lipiddroplet remodeling of yellow adipocytes. ${ }^{(21)}$ During fasting, bone marrow adipocytes (BMAC) do not serve as a fuel source and thus become the main provider of the circulating hormone adiponectin. ${ }^{(20)}$

\section{Adipocytes heterogeneity}

Adipocytes could be considered as quite heterogeneous cells. The same depot cells may be characterized by different functions. The WAT preadipocytes with a low CD9 expression level have higher adipogenic potential, whereas preadipocytes with a high CD9 expression level mostly display profibrotic and proinflammatory properties.(22) Based on single-cell transcriptome profiling, WAC could be divided into four subtypes, including beige thermogenic adipocytes and a subtype specialized in leptin secretion. ${ }^{(23)}$

BrAC differ in the thermogenic potential. Low thermogenic adipocytes have a decreased UCP-1 and adiponectin expression, and they contain larger fat droplets and fewer mitochondria. ${ }^{(24)}$ There are two BeAC types: ordinary $\mathrm{BeAC}$ and glycolytic $\mathrm{BeAC}(\mathrm{g}-\mathrm{BeAC}){ }^{(18)} \mathrm{g}-\mathrm{BeAC}$ control thermogenesis and glucose homeostasis in the absence of $\beta$-adrenergic stimulation. According to Chen et al., ${ }^{(18)}$ heat stress may induce $\mathrm{g}$-BeAC formation from white preadipocytes. ${ }^{(18)}$ The ratio of white, beige and brown adipocytes is unstable and may differ ${ }^{(25,26)}$ in various fat depots, depending on different environmental factors, such as stress, cold stimulation, diet, and lactation. Due to the ability of adipocytes to differentiate and de-differentiate into another cell type, the cell number and phenotype incidence may be variable in different fat depots. ${ }^{(27)}$ Figure 1 illustrates the 
development paths of different adipocyte types and subtypes. Myf5- MSCs are progenitors of WAC, which are able to differentiate into pink and beige adipocytes. Myf5+ MSCs are BrAC progenitors. The ultrastructural difference is shown (the lipid-droplet-nucleus-mitochondria ratio). Thermogenic adipocytes are reached by mitochondria, whereas fat storing cells are reached by lipid droplets.

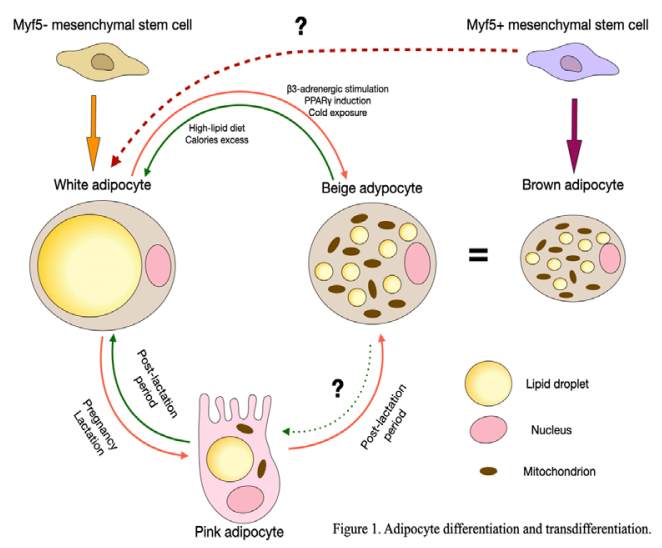

Fig. 1. Adipocyte differentiation and transdifferentiation.

\section{Adipocyte origin}

BAT develops during embryogenesis from the mesoderm, while BeAC are formed from WAC in the postnatal period. White preadipocytes develop from Myf5-negative progenitor cells during embryogenesis; differentiation of white preadipocytes in mature WAC occurs mostly postnatally.

The differentiation of WAC into BeAC is called WAT remodeling or browning. ${ }^{(13)} \mathrm{BrAC}$ and $\mathrm{BeAC}$ have different origins, but similar morphology and metabolic characteristics. Classic BrAC are derived from the Myf5-positive muscle progenitor cell line. ${ }^{(20)} \mathrm{BrAC}$ are usually localized together with WAC, for example, in the interscapular and perirenal regions. Moreover, in response to prolonged cold exposure or stimulation of $\beta$-adrenergic receptors, WAC acquire UCP1 expression, which results in a browning phenomenon and occurrence of Myf5-negative brown cell type. ${ }^{(29)}$ It should be mentioned that cold stimulation or administration of $\beta 3$ adrenergic receptor agonists unevenly increases the level of UCP-1 expression in white cells. This phenomenon is called the "Harlequin effect"-AT looks heterogeneously stained after immunostaining assay for UCP-1. ${ }^{(13,30)}$ However, chronic exposure to cold weakens this effect (cells are stained more evenly), which may be associated with increased expression of heat shock proteins protecting adipocytes from damage caused by overheating. ${ }^{(31)}$ At the same time, browning of neighboring WAC is efficiently stimulated, which allows heat to be distributed between cells more equally. ${ }^{(32)}$

According to Jeffery et al., ${ }^{(33)}$ the pathway of preadipocyte differentiation may depend on niche environmental local factors. It has been shown that donor preadipocytes isolated from subcutaneous and visceral depots undergo subsequent differentiation according to the injection site under high fat diet conditions, without any difference in place of origin; preadipocytes keep the ability to differentiate only in visceral, but not in subcutaneous, fat depot. ${ }^{(33)}$ According to recent studies, An increase in PPAR $\gamma$ expression level stimulates adipogenesis in fibroblast cultures. Nevertheless, it is unable to initiate adipogenesis in vivo in cases of the limited differentiation ability (in subcutaneous fat depot or during low fat diet). ${ }^{(34)}$ Based on this data, it is possible to raise the questions: Which factors guide differentiation of the precursor cells, what are the sources of these factors, and how is adipocyte differentiation regulated in different fat stores? These questions remain unresolved. Furthermore, different populations of stromal cells in various fat depots consist of several subpopulations, including cells with anti-adipogenic properties, which was shown in single-cell transcriptome profiling analysis. ${ }^{(35,36)}$ Thereby, AT is characterized by high plasticity and heterogeneity, which depends on different endogenous and exogenous factors. This phenomenon can be confirmed by differential gene expression in various human fat depots and different factors, affecting adipogenesis, as well as genes, differentially expressed in adipocyte progenitor cells. $^{(37,38)}$

\section{Stages of adipogenesis}

Adipogenesis is a process of multipotent MSC differentiation in adipocytes. ${ }^{(36)}$ WAC arise from MSCs localized in AT stroma. When MSCs become preadipocytes, they lose the ability to differentiate in other mesenchymal clones. This stage of adipogenesis is the determination phase. The second stage is terminal differentiation; in this step, preadipocytes acquire the characteristics of mature adipocytes by accumulating lipid droplets and gaining the ability to respond to endocrine stimuli. (39) Thus, MSCs differentiate into lipoblasts, then into preadipocytes and ultimately into mature adipocytes. ${ }^{(1)}$ According to the modern theory of the origin of adipocytes, precursor cells, endotheliocytes and pericytes are localized in the walls of adipose capillary beds ${ }^{(40)}$ Capillary explants from human AT, as well as a suspension of individual microvessel cells, may form adipocyte precursors, able to autonomously differentiate into mature fat cells. ${ }^{(41)}$ Moreover, according to experimental data, human adipocytes may de-differentiate into endothelial cells; ${ }^{\text {(42) }}$ endothelial cells can be de-differentiated into mesenchymal cells, which give rise to adipocytes, chondrocytes and osteoblasts. ${ }^{(43)}$ The mesenchymal-endothelial transition is associated with activation of the BMP/TGF $\beta$ signaling pathway. ${ }^{(44)}$ Besides, according to the latest clinical and experimental research, at least several subpopulations of adipocytes are derived from hematopoietic cells of BM. $\left({ }^{45)}\right.$ In addition, some studies have revealed a mesothelial origin of visceral adipocytes. ${ }^{(46)}$ Nevertheless, the problem of adipocyte biogenesis is still unsolved and being intensively investigated.

Adipogenesis of white and brown adipocytes requires activation of the same key transcription factors: PPAR $\gamma, \mathrm{C} / \mathrm{EBPs}$, Krüppel-like factor, as well as the signal transducers and activators of transcription (STAT) proteins. (1) Differentiation of adipocytes is also regulated by BMPs, which belong to the TGF $\beta$ superfamily. In this case, the differentiation of WAC is regulated by BMP-2 and BMP4 , while BMP-7 is a major factor in the differentiation of 
preadipocytes into mature BrAC. Moreover, an important regulator of brown and white adipocytes maturing is the activated p38 signaling pathway. ${ }^{(28)}$

Some of the universal markers of preadipocytes in WAT are PDGFR $\alpha$ and PPAR $\gamma$, expressed in progenitor cells, but not in mature adipocytes. PDGFR $\alpha+$ and PPAR $\gamma+$ cells are localized in the capillary walls in WAT depots. These cells are called pericytes. ${ }^{(34)}$ PPAR $\gamma+$ cells resemble smooth muscle cells of the blood vessels and express the same markers, such as $\alpha$ SMA ( $\alpha$-smooth muscle actin) and PDGFR $\beta{ }^{\left({ }^{(47)}\right.}$ Modern studies have shown that turning $\alpha \mathrm{SMA}+$ and PDGFR $\beta+$ cells into WAC may be induced in vivo by a high fat diet. ${ }^{(48)}$ However, a recent analysis of single-cell transcriptome profiling showed heterogeneity of adipocyte precursors from different fat depots. Additionally, there were described different stimuli, which are able to activate the differentiation of adipocyte precursors into mature adipocytes. ${ }^{(49)}$

Early studies on fibroblast cultures showed that BMP2 and BMP4, by activating transcription factor SMAD4, are able to initiate the differentiation of fibroblasts into adipocytes in vitro. ${ }^{(50)}$ SMAD4 stimulates the transcription of PPAR $\gamma$, the main regulator of adipogenesis. On the other hand, adipogenic fibroblasts are characterized by increased expression of transcription factor ZFP423 (zinc-finger transcription protein 423), which enhances the sensitivity of fibroblasts to proadipogenic BMP signaling. ${ }^{(51)}$ Furthermore, expression of ZFP423 is required for the formation of subcutaneous fat in the fetus, but it is not required for the formation of visceral fat in cases of a high fat diet. ${ }^{(49,52)}$ Many other factors directing fibroblast differentiation into adipocytes have been identified; however, the ways in which their expression is activated and regulated remain mostly unknown.

PPAR $\gamma$ is considered as the key regulator of adipogenesis, since its expression is absolutely required for terminal differentiation of preadipocytes, both in cell cultures and in vivo. ${ }^{(53,54)}$ According to recent publications, there are many molecules that could be considered endogenous PPAR $\gamma$ activator ligands. The most common are polyunsaturated FAs, eicosanoids, and prostaglandins. However, the affinity or concentration of such potential activators in AT is low; therefore, the true physiological ligand PPAR $\gamma$ is still unknown. ${ }^{(55)}$

One of the most important effects of PPAR $\gamma$ is the activation of transcription factor $\mathrm{C} / \mathrm{EBP} \alpha \cdot{ }^{(56)}$ According to Freytag et al., ${ }^{(57)}$ the induction of $\mathrm{C} / \mathrm{EBP} \alpha$ and PPAR $\gamma$ expression is sufficient for fibroblast differentiation into mature adipocytes in cell cultures.

More than $90 \%$ of binding sites PPAR $\gamma$ also bind to DNA and $\mathrm{C} / \mathrm{EBP} \alpha$. In order to completely activate transcription of genes expressed in mature adipocytes (for example, genes encoding insulin receptors, glucose transporters, adiponectin, adipocyte fatty acid-binding protein (aP2), perilipins, leptin, and others), PPAR $\gamma$ activates transcription of C/EBPs. ${ }^{(58)}$ However, $\mathrm{C} / \mathrm{EBP} \alpha$ expression is not required for adipogenesis activation during embryogenesis, possibly due to a high $\mathrm{C} /$ EBP $\beta$ expression level. The expression of $\mathrm{C} / \mathrm{EBP} \alpha^{(59)}$ is absolutely essential for all forms of adipogenesis in adult organisms also (Fig.2)
Adipocytes are energy storing mesenchymal cells. Adipogenesis may be divided into two stages: determination and terminal differentiation. In the first step, MSCs become able to differentiate into fat storing cells. Terminal differentiation is characterized by special morphological and functional properties of adipocyte development, including accumulation of lipid droplets.

WAT is considered as the most dynamic tissue in the human body, possessing high plasticity ${ }^{(60)}$ It is known that preadipocyte differentiation is not a unidirectional process, and under certain conditions, adipocytes are able to de-differentiate into fibroblast-like cells (Fig.2). This process is observed during wound healing, tumor growth and lactation. ${ }^{(61-63)}$ Additionally, the alveolar cells of the mammary gland may undergo the process of transdifferentiation (Fig.1). Furthermore, alveolar cells have shown an ability to transdifferentiate into BeAC in the early post-lactation period. ${ }^{(30)}$

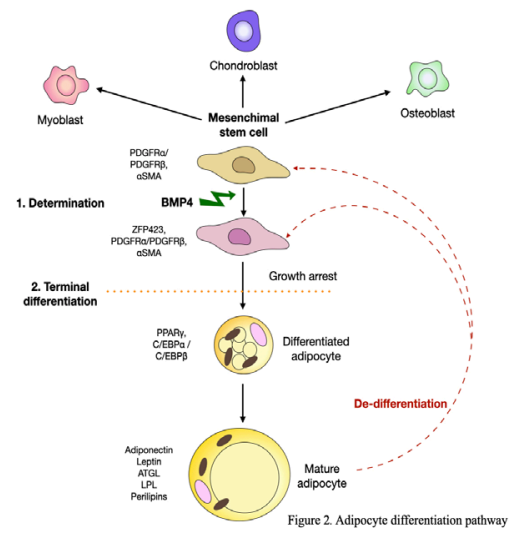

Fig. 2. Adipocyte differentiation pathways.

\section{Regulation of adipogenesis}

The increase in AT volume could be achieved in two ways: hypertrophy, the adipocytes' size increase; and/or hyperplasia, the cell number increase. According to the literature data, the number of adipocytes is genetically determined, thus, the number of WAC remains constant in adulthood both in lean and obese people and even after noticeable weight loss. Therefore, the fat mass in adults could be increased mostly by accumulation of lipids in already developed fat cells.

Recent studies in rodents based on radiolabeling showed subcutaneous preadipocyte differentiation during the embryonic period. The main mechanism of postnatal fat mass increase was suggested to be associated with hypertrophy. ${ }^{(65)} \mathrm{At}$ the same time, the development of visceral AT occurs mainly postnatally, equally both by hyperplasia and hypertrophy. ${ }^{(66)}$ Moreover, about $10 \%$ of adipocytes are annually renewed, and this process does not depend on BMI, age or environment. ${ }^{(64)}$

The early recruitment of new fat cells depends on crosstalking between Wnt and BMP-4 signals. Wnt amplifies proliferation of preadipocytes, while BMP-4 is responsible for their terminal differentiation into mature adipocytes. Wnt proteins inhibit adipogenesis, suppressing the expression of CEBP- $\alpha$ and PPAR $-\gamma^{(60)}$ Wnt proteins belong to a family of 
secreted glycoproteins regulating tissue remodeling in adults. Besides, Wnt signaling is required for cross-communication of fat cells. Wnt is the chief regulator of $\beta$-catenin, which participates in the coordination of gene transcription. In case of the Wnt low level, cytoplasmic $\beta$-catenin is phosphorylated by casein kinase I and kinase of glycogen synthase $3-\beta$, which leads to its ubiquitination and subsequent proteasome degradation.

Wnt binds to Frizzled (FZD) receptors and LDLR5/6, which inactivates the degradation complex. This leads to $\beta$-catenin hypophosphorylation and its translocation into the nucleus, where it binds to the lymphoid enhancer binding factor $1 / \mathrm{T}$ cell-specific factor (LEF1/TCF) to activate Wnt target genes (Fig.3).

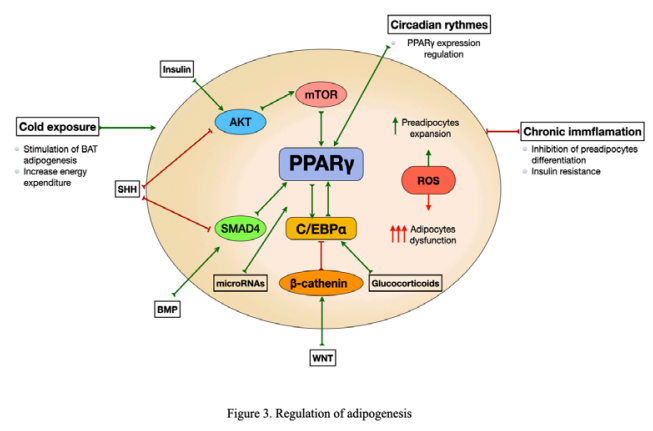

Fig. 3. Regulation of adipogenesis.

Intracellular pathways and extracellular stimuli affecting adipogenesis. Upregulation stimuli are indicated by green indicators. Downregulation stimuli are indicated by red indicators.

This damage to the signaling pathways is associated with adipogenesis dysregulation and the organism's inability to regulate the accumulation of lipids in subcutaneous AT in response to environmental factors. This leads to hypertrophy, dysfunction and the development of insulin resistance. GLUT4 synthesis and activation decrease and glucose transport into adipocytes is reduced. ${ }^{(67)}$

One of the most crucial roles in adipogenesis regulation belongs to ROS, the formation of which affects stability of the HIF- $1 \alpha$ that inhibits PPAR- $\gamma \cdot{ }^{(60)}$ It has also been shown that ROS in physiological concentrations has the ability to enhance insulin signaling, which stimulates adipogenesis, ${ }^{(68)}$ However, high ROS levels, produced by NADPH oxidases during obesity, are associated with development of insulin resistance and suppression of adipogenesis. ${ }^{(69)}$

MicroRNAs provide an additional mechanism of adipogenesis control. ${ }^{(60)}$ According to recent studies, some miRNAs inhibit the expression of leukemia inhibitory factor (LIF), which leads to adipogenesis activation. For example, microRNA-130, microRNA-378 and microRNA-27 control the expression of adipogenic and lipogenic genes. ${ }^{(60)}$

The most important pro-adipogenic properties reside in glucocorticoid hormones and insulin, which directly affect the expression of PPAR $\gamma$ and $\mathrm{C} / \mathrm{EBP} \alpha$ transcription factors, guiding preadipocyte differentiation. ${ }^{(70,71)}$ In contrast, the Hedgehog signaling pathway inhibits adipogenesis by suppressing pro-adipogenic signaling cascades. $^{(72)}$ Other regulatory factors of adipogenesis include cold-dependent $\beta 3$ adrenergic stimulation, ${ }^{(73)}$ proinflammatory molecules, TGF $\beta$, and NO. The physiological concentrations of these factors are important stimulators of adipogenesis; however, chronic inflammation suppresses adipogenesis as a high level of proinflammatory factors accelerates cell aging and enhances metabolic imbalance. ${ }^{(74,75)}$ PPAR $\gamma$ expression depends on circadian rhythms; therefore, development of obesity and dysregulation of adipogenesis are associated with disruption of circadian rhythms ${ }^{(76)}$ (Fig.3).

\section{Adipocyte senescence and death}

Human adipocytes live for approximately 10 years. During this period triacylglycerols (TAGs) in adipocytes are renewed about 6 times. It has been shown that adipocytic TAGs are constantly metabolized and there are no constitutive TAGs that do not undergo lipolysis. ${ }^{(77)}$

Age-related BAT reduction occurs due to a reduction in stem cells' reproductive capacity, diminished production of triiodothyronine and low conversion of thyroxine to triiodothyronine, mitochondrial dysfunction and decreased sympathetic activity of the nervous system. ${ }^{(78)}$ The modern developmental theory states that chronic inflammation should be considered as a key factor of aging or tissue senescence. ${ }^{(79)}$ The cell number of macrophages and T-lymphocytes, secreting certain factors, increases in AT, and that leads to damage and degeneration of the surrounding cells and development of chronic inflammation (called "inflammaging"). ${ }^{(80)}$

Senescence of adipocytes has been studied based on profiling of gene and secretory $\beta$-galactosidase activity in paired biopsies of subcutaneous and omental AT in severely obese patients. The activity of $\beta$-galactosidase is seven times higher in the subcutaneous AT than in the omental AT. Furthermore, it has been shown that higher $\beta$-galactosidase activity is associated with a high serum leptin level, severe dyslipidemia, and development of insulin resistance. According to Rouault et al. ${ }^{(81)}$ levels of several factors, such as IGFBP-3, PAI-1, CCL2, and IL-6, were increased in senescent subcutaneous AT. Senolytic treatment reduced $\beta$-galactosidase activity and led to normalizing the levels of the factors. ${ }^{(81)}$

Obese people have a variety of metabolic changes. As adipocytes increase, cells undergo mechanical stress, since they begin to contact neighboring cells and components of the extracellular matrix. ${ }^{(82)}$ In addition, hypoxia develops due to limited diffusion of oxygen to adipocytes. Mechanical and hypoxic stress leads to the development of inflammation, which is accompanied by increased lipolysis, secretion of inflammatory cytokines and decreased secretion of antiinflammatory adipokines such as leptin and adiponectin. ${ }^{(82)}$ In addition, the size of adipocytes is positively correlated with the number of CD206+ macrophages involved in phagocytosis of dead cells. ${ }^{(83)}$ Thus, not the obesity itself, but the exact size of adipocytes is a key factor responsible for their death. Death size is the cell size; when that size is reached, cell death is induced. Visceral adipocytes have a smaller critical death size than subcutaneous adipocytes. ${ }^{(30)}$ 
In hypertrophied adipocytes, a number of important pathological changes are observed: changes in the number and size of mitochondria, hypertrophy of the endoplasmic reticulum and the Golgi apparatus, which is associated with other causes of overproduction of proinflammatory factors, such as MCP-1, MIP-1 $\alpha$, MCP-2, MCP-3, RANTES. Accumulation of cholesterol granules and overproduction of collagen and amyloid in the extracellular matrix also occurs. ${ }^{(84-86)}$ Cholesterol presence and modification of cell organelles are potential molecular patterns associated with cell damage (DAMPs, damage-associated-molecular patterns) because they act as activators of NLR receptors (Nucleotide oligomerization domain [NOD]-like receptors). These receptors together with procaspase-1 and PYCARD (apoptosis-associated speck-like protein containing a CARD [C-terminal caspase recruitment domain]) form a unified protein complex. ${ }^{(87)}$ Activation of NLRs leads to the formation of active caspase-1, which initiates a special type of cell death associated with hyperinflammation-pyroptosis. ${ }^{(88)}$ Given that the number of cells producing inflammatory factors increases with age, more adipocytes undergo pyroptosis, which leads to greater hypertrophy of remaining cells and the development of metabolic disorders associated with their hypertrophy.

However, about $20 \%-30 \%$ of the total cohort of obese patients are metabolically healthy people. Moreover, clinical studies have shown beneficial effects of adipogenesis stimulation, improving metabolic health in people with low BMI. For example, people who are predisposed to hypertrophic obesity have a reduced insulin sensitivity; therefore, these patients develop insulin resistance even with normal body weight, without obesity. Besides, inhibition of adipogenesis during adulthood by deletion of PPAR $\gamma$ leads to pathological hypertrophic expansion of WAT in conditions of overnutrition. In contrast, the stimulation of visceral adipogenesis by PPAR $\gamma$ overexpression leads to beneficial effects: decrease in the level of local inflammation and maintenance of normal secretion of adiponectin without weight gain. Additionally, impaired adipogenesis may lead to inability to sequester lipotoxic FAs. ${ }^{(89)}$

\section{Adipocytes signaling molecules}

The endocrine function of AT is well known. AT secretes hormones, cytokines, and protein growth factors like leptin, adiponectin, resistin, visfatin, apelin, asprosin, and FGF21 (Fig.4), all of which affect various organs.. The signaling molecules and target organs are presented in Figure 2. The font is increased for the main signaling molecules. These factors have many targets of action (liver, skeletal muscles, nervous tissue, heart, intestines, pancreas, etc.) and play an important role in their functions and metabolism regulation. ${ }^{(90)}$

However, new signaling molecules formed by AT were recently identified. These molecules include FAHFAs and diHOMEs. ${ }^{(2)}$ Most studied FAHFAs are compounds of palmitic acid with hydroxystearate. The FAHFA level is increased in mice with high GLUT-4 expression in AT and in animals with a metabolically healthy phenotype. FAHFAs also exhibit anti- inflammatory properties, reducing lipopolysaccharide-induced macrophage activation. ${ }^{(2,91)}$ Lipokine diHOME is a product of linoleic acid metabolism (12,13-dihydroxy-9Z-octadenoic acid or 12,13-diHOME). A high level of 12,13-diHOME is found in WAT, where it increases the utilization of FFA. Physical activity and cold exposure are positively correlated with high levels of 12,13-diHOME in blood serum, due to its regulatory role in the process of free FA oxidation in myocytes. ${ }^{(9,92)}$

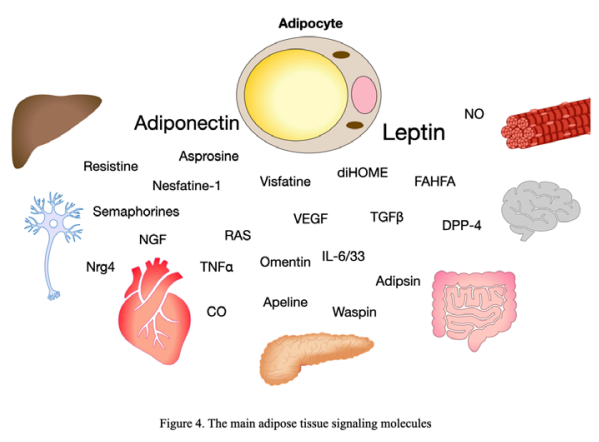

Fig. 4. The main adipose tissue signaling molecules.

\section{Conclusion}

Despite the extreme complexity of adipocyte origin issues, the molecular mechanisms of their formation, and their metabolic role in AT, the concept of adipogenesis takes shape as a multi-stage process of MSC differentiation. At the same time, preadipocytes are believed to have heterogeneity, plasticity, and perivascular origin. Precursors of adipocytes have also been found outside the main fat depots and play an important role in the processes of regenerating skin, bone, and muscle tissues and regulating their metabolism. An important adipocyte characteristic is an ability to return to the original fibroblast-like cell state, as well as the ability to transdifferentiate into a different type of adipose or nonAT. Adipogenesis and the pathway of mature adipocyte transformation depend on many factors that have systemic (action of hormones, cold stimulation, circadian rhythms) and local nature (influence of the microenvironment, paraand autocrine factors). Rate of adipogenesis and metabolic function of AT have an exceptional impact on the body's health and life expectancy. Adipogenesis plays an important role in general metabolism regulation and allows sequestering lipids, preventing their lipotoxic effect on other tissues. Thus, new therapeutic regulators of adipogenesis development may be potentially useful for the treatment of obesity, type 2 diabetes and other metabolic disorders, as well as for regenerative therapy.

\section{Competing Interests}

The authors declare that they have no competing interests. 


\section{References}

1. Bahmad HF, Daouk R, Azar J, Sapudom J, Teo JCM, Abou-Kheir W, et al. Modeling Adipogenesis: Current and Future Perspective. Cells. 2020 Oct 20;9(10):2326. doi: 10.3390/cells9102326.

2. Kahn CR, Wang G, Lee KY. Altered adipose tissue and adipocyte function in the pathogenesis of metabolic syndrome. J Clin Invest. 2019 Oct 1;129(10):3990-4000. doi: 10.1172/ JCI129187.

3. Suchacki KJ, Tavares AAS, Mattiucci D, Scheller EL, Papanastasiou G, Gray C, et al. Bone marrow adipose tissue is a unique adipose subtype with distinct roles in glucose homeostasis. Nat Commun. 2020 Jun 18;11(1):3097. doi: 10.1038/s41467-020-16878-2.

4. Driskell RR, Jahoda CA, Chuong CM, Watt FM, Horsley V. Defining dermal adipose tissue. Exp Dermatol. 2014 Sep;23(9):629-31. doi: 10.1111/exd.12450.

5. Debette S, Beiser A, Hoffmann U, Decarli C, O’Donnell CJ, Massaro JM, et al. Visceral fat is associated with lower brain volume in healthy middle-aged adults. Ann Neurol. 2010 Aug;68(2):136-44. doi: 10.1002/ana.22062.

6. Fox CS, Massaro JM, Hoffmann U, Pou KM, Maurovich-Horvat P, Liu CY, et al. Abdominal visceral and subcutaneous adipose tissue compartments: association with metabolic risk factors in the Framingham Heart Study. Circulation. 2007 Jul 3;116(1):39-48. doi: 10.1161/ CIRCULATIONAHA.106.675355.

7. Speliotes EK, Massaro JM, Hoffmann U, Vasan RS, Meigs JB, Sahani DV, et al. Fatty liver is associated with dyslipidemia and dysglycemia independent of visceral fat: the Framingham Heart Study. Hepatology. 2010 Jun;51(6):197987. doi: 10.1002/hep.23593.

8. Enzi G, Busetto L, Sergi G, Coin A, Inelmen EM, Vindigni $\mathrm{V}$, et al. Multiple symmetric lipomatosis: a rare disease and its possible links to brown adipose tissue. Nutr Metab Cardiovasc Dis. 2015 Apr;25(4):347-53. doi: 10.1016/j. numecd.2015.01.010.

9. Ortega-Molina A, Efeyan A, Lopez-Guadamillas E, Muñoz-Martin M, Gómez-López G, Cañamero M, et al. Pten positively regulates brown adipose function, energy expenditure, and longevity. Cell Metab. 2012 Mar 7;15(3):38294. doi: 10.1016/j.cmet.2012.02.001.

10. Cereijo R, Gallego-Escuredo JM, Moure R, Villarroya J, Domingo JC, Fontdevila J, et al. The Molecular Signature of HIV-1-Associated Lipomatosis Reveals Differential Involvement of Brown and Beige/Brite Adipocyte Cell Lineages. PLoS One. 2015 Aug 25;10(8):e0136571. doi: 10.1371/journal.pone.0136571.

11. Grundy SM. Adipose tissue and metabolic syndrome: too much, too little or neither. Eur J Clin Invest. 2015 Nov;45(11):1209-17. doi: 10.1111/eci.12519. Epub 2015 Sep 13.

12. Huang-Doran I, Sleigh A, Rochford JJ, O'Rahilly S, Savage DB. Lipodystrophy: metabolic insights from a rare disorder. J Endocrinol. 2010 Dec;207(3):245-55. doi: 10.1677/ JOE-10-0272.

13. Rui L. Brown and Beige Adipose Tissues in Health and Disease. Compr Physiol. 2017 Sep 12;7(4):1281-1306. doi: 10.1002/cphy.c170001.
14. Pinckard KM, Shettigar VK, Wright KR, Abay E, Baer LA, Vidal P, et al. A Novel Endocrine Role for the BATReleased Lipokine 12,13-diHOME to Mediate Cardiac Function. Circulation. 2021 Jan 12;143(2):145-159. doi: 10.1161/CIRCULATIONAHA.120.049813.

15. Sbarbati A, Morroni M, Zancanaro C, Cinti S. Rat interscapular brown adipose tissue at different ages: a morphometric study. Int J Obes. 1991 Sep;15(9):581-7.

16. Rossato M. Aging and brown adipose tissue activity decline in human: does the brain extinguish the fire? Aging Clin Exp Res. 2016 Jun;28(3):579-81. doi: 10.1007/s40520016-0572-z.

17. Vijgen GH, Bouvy ND, Teule GJ, Brans B, Schrauwen $P$, van Marken Lichtenbelt WD. Brown adipose tissue in morbidly obese subjects. PLoS One. 2011 Feb 24;6(2):e17247. doi: 10.1371/journal.pone.0017247.

18. Chen Y, Ikeda K, Yoneshiro T, Scaramozza A, Tajima $\mathrm{K}$, Wang Q, et al. Thermal stress induces glycolytic beige fat formation via a myogenic state. Nature. 2019 Jan;565(7738):180-185. doi: 10.1038/s41586-018-0801-z.

19. Craft CS, Robles H, Lorenz MR, Hilker ED, Magee KL, Andersen TL, et al. Bone marrow adipose tissue does not express UCP1 during development or adrenergic-induced remodeling. Sci Rep. 2019 Nov 22;9(1):17427. doi: 10.1038/ s41598-019-54036-x.

20. Cawthorn WP, Scheller EL, Learman BS, Parlee SD, Simon BR, Mori H, et al. Bone marrow adipose tissue is an endocrine organ that contributes to increased circulating adiponectin during caloric restriction. Cell Metab. 2014 Aug 5;20(2):368-375. doi: 10.1016/j.cmet.2014.06.003.

21. Scheller EL, Khandaker S, Learman BS, Cawthorn WP, Anderson LM, Pham HA, et al. Bone marrow adipocytes resist lipolysis and remodeling in response to $\beta$-adrenergic stimulation. Bone. 2019 Jan;118:32-41. doi: 10.1016/j. bone.2018.01.016.

22. Marcelin G, Ferreira A, Liu Y, Atlan M, Aron-Wisnewsky J, Pelloux V, et al. A PDGFR $\alpha$-Mediated Switch toward CD9high Adipocyte Progenitors Controls Obesity-Induced Adipose Tissue Fibrosis. Cell Metab. 2017 Mar 7;25(3):673685. doi: 10.1016/j.cmet.2017.01.010.

23. Rojas-Rodriguez R, Lujan-Hernandez J, Min SY, DeSouza T, Teebagy P, Desai A, et al. 2019 Jun;25(11-12):842-854. doi: 10.1089/ten.TEA.2018.0067.

24. Song A, Dai W, Jang MJ, Medrano L, Li Z, Zhao H, et al. Low- and high-thermogenic brown adipocyte subpopulations coexist in murine adipose tissue. J Clin Invest. 2020 Jan 2;130(1):247-257. doi: 10.1172/JCI129167.

25. Esteve Ràfols M. Adipose tissue: cell heterogeneity and functional diversity. Endocrinol Nutr. 2014 Feb;61(2):100-12. English, Spanish. doi: 10.1016/j.endonu.2013.03.011.

26. Ibrahim MM. Subcutaneous and visceral adipose tissue: structural and functional differences. Obes Rev. 2010 Jan;11(1):11-8. doi: 10.1111/j.1467-789X.2009.00623.x.

27. Pellegrinelli V, Carobbio S, Vidal-Puig A. Adipose tissue plasticity: how fat depots respond differently to pathophysiological cues. Diabetologia. 2016 Jun;59(6):107588. doi: 10.1007/s00125-016-3933-4.

28. Leiva M, Matesanz N, Pulgarín-Alfaro M, Nikolic I, Sabio G. Uncovering the Role of p38 Family Members in Adipose Tissue Physiology. Front Endocrinol (Lausanne). 2020 Dec 
23;11:572089. doi: 10.3389/fendo.2020.572089.

29. Bozec A, Hannemann N. Mechanism of Regulation of Adipocyte Numbers in Adult Organisms Through Differentiation and Apoptosis Homeostasis. J Vis Exp. 2016 Jun 3;(112):53822. doi: 10.3791/53822.

30. Cinti S. Adipose Organ Development and Remodeling. Compr Physiol. 2018 Sep 14;8(4):1357-1431. doi: 10.1002/ cphy.c170042.

31. Morroni M, Barbatelli G, Zingaretti MC, Cinti S. Immunohistochemical, ultrastructural and morphometric evidence for brown adipose tissue recruitment due to cold acclimation in old rats. Int J Obes Relat Metab Disord. 1995 Feb;19(2):126-31.

32. Lee YH, Petkova AP, Konkar AA, Granneman JG. Cellular origins of cold-induced brown adipocytes in adult mice. FASEB J. 2015 Jan;29(1):286-99. doi: 10.1096/fj.14263038.

33. Jeffery E, Wing A, Holtrup B, Sebo Z, Kaplan JL, SaavedraPeña R, et al. The Adipose Tissue Microenvironment Regulates Depot-Specific Adipogenesis in Obesity. Cell Metab. $2016 \mathrm{Jul}$ 12;24(1):142-50. doi: 10.1016/j.cmet.2016.05.012.

34. Lee YH, Petkova AP, Mottillo EP, Granneman JG. In vivo identification of bipotential adipocyte progenitors recruited by $\beta 3$-adrenoceptor activation and high-fat feeding. Cell Metab. 2012 Apr 4;15(4):480-91. doi: 10.1016/j.cmet.2012.03.009.

35. Burl RB, Ramseyer VD, Rondini EA, Pique-Regi R, Lee YH, Granneman JG. Deconstructing Adipogenesis Induced by $\beta 3$-Adrenergic Receptor Activation with Single-Cell Expression Profiling. Cell Metab. 2018 Aug 7;28(2):300-309. e4. doi: 10.1016/j.cmet.2018.05.025.

36. Schwalie PC, Dong H, Zachara M, Russeil J, Alpern $\mathrm{D}$, Akchiche N, et al. A stromal cell population that inhibits adipogenesis in mammalian fat depots. Nature. 2018 Jul;559(7712):103-108. doi: 10.1038/s41586-018-0226-8.

37. Mota de Sá P, Richard AJ, Hang H, Stephens JM. Transcriptional Regulation of Adipogenesis. Compr Physiol. 2017 Mar 16;7(2):635-674. doi: 10.1002/cphy.c160022.

38. Ghaben AL, Scherer PE. Adipogenesis and metabolic health. Nat Rev Mol Cell Biol. 2019 Apr;20(4):242-258. doi: 10.1038/s41580-018-0093-z.

39. Sarjeant K, Stephens JM. Adipogenesis. Cold Spring Harb Perspect Biol. 2012 Sep 1;4(9):a008417. doi: 10.1101/ cshperspect.a008417.

40. Berry R, Rodeheffer MS. Characterization of the adipocyte cellular lineage in vivo. Nat Cell Biol. 2013 Mar;15(3):302-8. doi: $10.1038 /$ ncb2696.

41. Min SY, Kady J, Nam M, Rojas-Rodriguez R, Berkenwald A, Kim JH, Noh HL, et al. Human 'brite/beige' adipocytes develop from capillary networks, and their implantation improves metabolic homeostasis in mice. Nat Med. 2016 Mar;22(3):312-8. doi: 10.1038/nm.4031.

42. Planat-Benard V, Silvestre JS, Cousin B, André M, Nibbelink M, Tamarat R, et al. Plasticity of human adipose lineage cells toward endothelial cells: physiological and therapeutic perspectives. Circulation. 2004 Feb 10;109(5):65663. doi: 10.1161/01.CIR.0000114522.38265.61.

43. Medici D, Shore EM, Lounev VY, Kaplan FS, Kalluri $\mathrm{R}$, Olsen BR. Conversion of vascular endothelial cells into multipotent stem-like cells. Nat Med. 2010 Dec;16(12):14006. doi: 10.1038/nm.2252.
44. Maddaluno L, Rudini N, Cuttano R, Bravi L, Giampietro C, Corada M, et al. EndMT contributes to the onset and progression of cerebral cavernous malformations. Nature. 2013 Jun 27;498(7455):492-6. doi: 10.1038/nature12207.

45. Horowitz MC, Berry R, Holtrup B, Sebo Z, Nelson T, Fretz JA, et al. Bone marrow adipocytes. Adipocyte. $2017 \mathrm{Jul}$ 3;6(3):193-204. doi: 10.1080/21623945.2017.1367881.

46. Chau YY, Bandiera R, Serrels A, Martínez-Estrada OM, Qing W, Lee M, et al. Visceral and subcutaneous fat have different origins and evidence supports a mesothelial source. Nat Cell Biol. 2014 Apr;16(4):367-75. doi: 10.1038/ ncb2922.

47. Tang W, Zeve D, Suh JM, Bosnakovski D, Kyba M, Hammer RE, et al. White fat progenitor cells reside in the adipose vasculature. Science. 2008 Oct 24;322(5901):583-6. doi: 10.1126/science. 1156232.

48. Vishvanath L, MacPherson KA, Hepler C, Wang QA, Shao M, Spurgin SB, et al. Pdgfr $\beta+$ Mural Preadipocytes Contribute to Adipocyte Hyperplasia Induced by HighFat-Diet Feeding and Prolonged Cold Exposure in Adult Mice. Cell Metab. 2016 Feb 9;23(2):350-9. doi: 10.1016/j. cmet.2015.10.018.

49. Hepler C, Shao M, Xia JY, Ghaben AL, Pearson MJ, Vishvanath L, et al. Directing visceral white adipocyte precursors to a thermogenic adipocyte fate improves insulin sensitivity in obese mice. Elife. 2017 Jul 19;6:e27669. doi: 10.7554/eLife.27669.

50. Huang H, Song TJ, Li X, Hu L, He Q, Liu M, et al. BMP signaling pathway is required for commitment of C3H10T1/2 pluripotent stem cells to the adipocyte lineage. Proc Natl Acad Sci U S A. 2009 Aug 4;106(31):12670-5. doi: 10.1073/ pnas.0906266106.

51. Gupta RK, Arany Z, Seale P, Mepani RJ, Ye L, Conroe HM, et al. Transcriptional control of preadipocyte determination by Zfp423. Nature. 2010 Mar 25;464(7288):619-23. doi: 10.1038/nature08816.

52. Shao M, Hepler C, Vishvanath L, MacPherson KA, Busbuso NC, Gupta RK. Fetal development of subcutaneous white adipose tissue is dependent on Zfp423. Mol Metab. 2016 Nov 21;6(1):111-124. doi: 10.1016/j.molmet.2016.11.009.

53. Barak Y, Nelson MC, Ong ES, Jones YZ, Ruiz-Lozano $\mathrm{P}$, Chien KR, et al. PPAR gamma is required for placental, cardiac, and adipose tissue development. Mol Cell. 1999 Oct;4(4):585-95. doi: 10.1016/s1097-2765(00)80209-9.

54. Rosen ED, Sarraf P, Troy AE, Bradwin G, Moore $\mathrm{K}$, Milstone DS, et al. PPAR gamma is required for the differentiation of adipose tissue in vivo and in vitro. Mol Cell. 1999 Oct;4(4):611-7. doi: 10.1016/s1097-2765(00)80211-7. 55. Schupp M, Lazar MA. Endogenous ligands for nuclear receptors: digging deeper. J Biol Chem. 2010 Dec 24;285(52):40409-15. doi: 10.1074/jbc.R110.182451.

56. Wu Z, Rosen ED, Brun R, Hauser S, Adelmant G, Troy AE, et al. Cross-regulation of C/EBP alpha and PPAR gamma controls the transcriptional pathway of adipogenesis and insulin sensitivity. Mol Cell. 1999 Feb;3(2):151-8. doi: 10.1016/s1097-2765(00)80306-8.

57. Freytag SO, Paielli DL, Gilbert JD. Ectopic expression of the CCAAT/enhancer-binding protein alpha promotes the adipogenic program in a variety of mouse fibroblastic cells. Genes Dev. 1994 Jul 15;8(14):1654-63. doi: 10.1101/ 
gad.8.14.1654.

58. Lefterova MI, Zhang Y, Steger DJ, Schupp M, Schug J, Cristancho A, et al. PPARgamma and C/EBP factors orchestrate adipocyte biology via adjacent binding on a genome-wide scale. Genes Dev. 2008 Nov 1;22(21):2941-52. doi: $10.1101 / \mathrm{gad} .1709008$.

59. Wang QA, Tao C, Jiang L, Shao M, Ye R, Zhu Y, et al. Distinct regulatory mechanisms governing embryonic versus adult adipocyte maturation. Nat Cell Biol. 2015 Sep;17(9):1099-111. doi: 10.1038/ncb3217.

60. Lowe CE, O'Rahilly S, Rochford JJ. Adipogenesis at a glance. J Cell Sci. 2011 Aug 15;124(Pt 16):2681-6. doi: 10.1242/jcs.079699.

61. Plikus MV, Guerrero-Juarez CF, Ito M, Li YR, Dedhia PH, Zheng Y, et al. Regeneration of fat cells from myofibroblasts during wound healing. Science. 2017 Feb 17;355(6326):748752. doi: 10.1126/science.aai8792.

62. Bi P, Yue F, Karki A, Castro B, Wirbisky SE, Wang C, et al. Notch activation drives adipocyte dedifferentiation and tumorigenic transformation in mice. J Exp Med. 2016 Sep 19;213(10):2019-37. doi: 10.1084/jem.20160157.

63. Wang QA, Song A, Chen W, Schwalie PC, Zhang F, Vishvanath L, et al. Reversible De-differentiation of Mature White Adipocytes into Preadipocyte-like Precursors during Lactation. Cell Metab. 2018 Aug 7;28(2):282-288.e3. doi: 10.1016/j.cmet.2018.05.022.

64. Spalding KL, Arner E, Westermark PO, Bernard S, Buchholz BA, Bergmann O, et al. Dynamics of fat cell turnover in humans. Nature. 2008 Jun 5;453(7196):783-7. doi: 10.1038/nature06902.

65. Wang QA, Tao C, Gupta RK, Scherer PE. Tracking adipogenesis during white adipose tissue development, expansion and regeneration. Nat Med. 2013 Oct;19(10):133844. doi: $10.1038 / \mathrm{nm} .3324$.

66. Jeffery E, Church CD, Holtrup B, Colman L, Rodeheffer MS. Rapid depot-specific activation of adipocyte precursor cells at the onset of obesity. Nat Cell Biol. 2015 Apr; 17(4):37685. doi: $10.1038 / \mathrm{ncb} 3122$.

67. Smith U, Kahn BB. Adipose tissue regulates insulin sensitivity: role of adipogenesis, de novo lipogenesis and novel lipids. J Intern Med. 2016 Nov;280(5):465-475. doi: 10.1111/joim.12540.

68. Mahadev K, Motoshima H, Wu X, Ruddy JM, Arnold $\mathrm{RS}$, Cheng G, et al. The NAD(P)H oxidase homolog Nox4 modulates insulin-stimulated generation of $\mathrm{H} 2 \mathrm{O} 2$ and plays an integral role in insulin signal transduction. Mol Cell Biol. 2004 Mar;24(5):1844-54. doi: 10.1128/MCB.24.5.18441854.2004.

69. Furukawa S, Fujita T, Shimabukuro M, Iwaki M, Yamada Y, Nakajima Y, et al. Increased oxidative stress in obesity and its impact on metabolic syndrome. J Clin Invest. 2004 Dec;114(12):1752-61. doi: 10.1172/JCI21625.

70. Bäck K, Arnqvist HJ. Changes in insulin and IGF-I receptor expression during differentiation of human preadipocytes. Growth Horm IGF Res. 2009 Apr;19(2):10111. doi: 10.1016/j.ghir.2008.06.004.

71. Chapman AB, Knight DM, Ringold GM. Glucocorticoid regulation of adipocyte differentiation: hormonal triggering of the developmental program and induction of a differentiationdependent gene. J Cell Biol. 1985 Oct;101(4):1227-35. doi: 10.1083/jcb.101.4.1227.

72. Fontaine C, Cousin W, Plaisant M, Dani C, Peraldi P. Hedgehog signaling alters adipocyte maturation of human mesenchymal stem cells. Stem Cells. 2008 Apr;26(4):103746. doi: 10.1634/stemcells.2007-0974.

73. Wang W, Seale P. Control of brown and beige fat development. Nat Rev Mol Cell Biol. 2016 Nov;17(11):691702. doi: 10.1038/nrm.2016.96.

74. Weisberg SP, McCann D, Desai M, Rosenbaum M, Leibel RL, Ferrante AW Jr. Obesity is associated with macrophage accumulation in adipose tissue. $\mathrm{J}$ Clin Invest. 2003 Dec;112(12):1796-808. doi: 10.1172/JCI19246.

75. Alessi MC, Bastelica D, Morange P, Berthet B, Leduc I, Verdier $M$, et al. Plasminogen activator inhibitor 1 , transforming growth factor-beta1, and BMI are closely associated in human adipose tissue during morbid obesity. Diabetes. 2000 Aug;49(8):1374-80. doi: 10.2337/ diabetes.49.8.1374.

76. Sun M, Feng W, Wang F, Li P, Li Z, Li M, et al. Metaanalysis on shift work and risks of specific obesity types. Obes Rev. 2018 Jan;19(1):28-40. doi: 10.1111/obr.12621.

77. Spalding KL, Bernard S, Näslund E, Salehpour M, Possnert $\mathrm{G}$, Appelsved L, et al. Impact of fat mass and distribution on lipid turnover in human adipose tissue. Nat Commun. 2017 May 23;8:15253. doi: 10.1038/ncomms 15253.

78. Graja A, Schulz TJ. Mechanisms of aging-related impairment of brown adipocyte development and function. Gerontology. 2015;61(3):211-7. doi: 10.1159/000366557.

79. Franceschi C. Healthy ageing in 2016: Obesity in geroscience - is cellular senescence the culprit? Nat Rev Endocrinol. 2017 Feb;13(2):76-78. doi: 10.1038/ nrendo.2016.213.

80. Franceschi C, Garagnani P, Vitale G, Capri M, Salvioli S. Inflammaging and 'Garb-aging'. Trends Endocrinol Metab. 2017 Mar;28(3):199-212. doi: 10.1016/j.tem.2016.09.005.

81. Rouault C, Marcelin G, Adriouch S, Rose C, Genser L, Ambrosini M, et al. Senescence-associated $\beta$-galactosidase in subcutaneous adipose tissue associates with altered glycaemic status and truncal fat in severe obesity. Diabetologia. 2021 Jan;64(1):240-254. doi: 10.1007/s00125-020-05307-0..

82. Halberg N, Khan T, Trujillo ME, Wernstedt-Asterholm I, Attie AD, Sherwani S, et al. Hypoxia-inducible factor 1alpha induces fibrosis and insulin resistance in white adipose tissue. Mol Cell Biol. 2009 Aug;29(16):4467-83. doi: 10.1128/ MCB.00192-09.

83. Murano I, Barbatelli G, Parisani V, Latini C, Muzzonigro G, Castellucci M, et al. Dead adipocytes, detected as crownlike structures, are prevalent in visceral fat depots of genetically obese mice. J Lipid Res. 2008 Jul;49(7):1562-8. doi: 10.1194/ jlr.M800019-JLR200.

84. Kanda H, Tateya S, Tamori Y, Kotani K, Hiasa K, Kitazawa R, et al. MCP-1 contributes to macrophage infiltration into adipose tissue, insulin resistance, and hepatic steatosis in obesity. J Clin Invest. 2006 Jun;116(6):1494-505. doi: 10.1172/JCI26498.

*Corresponding author: Anastasia A. Zabolotneva. N. I. Pirogov Russian National Research Medical University. Moscow, Russia.E-mail: a.zabolotneva@gmail.com 
85. Sun K, Kusminski CM, Scherer PE. Adipose tissue remodeling and obesity. J Clin Invest. 2011 Jun;121(6):2094101. doi: 10.1172/JCI45887.

86. Xu H, Barnes GT, Yang Q, Tan G, Yang D, Chou CJ, et al. Chronic inflammation in fat plays a crucial role in the development of obesity-related insulin resistance. J Clin Invest. 2003 Dec;112(12):1821-30. doi: 10.1172/JCI19451. 87. Duewell P, Kono H, Rayner KJ, Sirois CM, Vladimer G, Bauernfeind FG, et al. NLRP3 inflammasomes are required for atherogenesis and activated by cholesterol crystals. Nature. 2010 Apr 29;464(7293):1357-61. doi: 10.1038/nature08938.

88. Martinon F, Tschopp J. Inflammatory caspases and inflammasomes: master switches of inflammation. Cell Death Differ. 2007 Jan;14(1):10-22. doi: 10.1038/sj.cdd.4402038.
89. Petrus P, Mejhert N, Corrales P, Lecoutre S, Li Q, Maldonado E, et al. Transforming Growth Factor- $\beta 3$ Regulates Adipocyte Number in Subcutaneous White Adipose Tissue. Cell Rep. 2018 Oct 16;25(3):551-560.e5. doi: 10.1016/j. celrep.2018.09.069.

90. Galic S, Oakhill JS, Steinberg GR. Adipose tissue as an endocrine organ. Mol Cell Endocrinol. 2010 Mar 25;316(2):129-39. doi: 10.1016/j.mce.2009.08.018.

91. Kuda O. Bioactive metabolites of docosahexaenoic acid. Biochimie. 2017 May;136:12-20. doi: 10.1016/j. biochi.2017.01.002.

92. Vidal P, Stanford KI. Exercise-Induced Adaptations to Adipose Tissue Thermogenesis. Front Endocrinol (Lausanne). 2020 Apr 29;11:270. doi: 10.3389/fendo.2020.00270. 